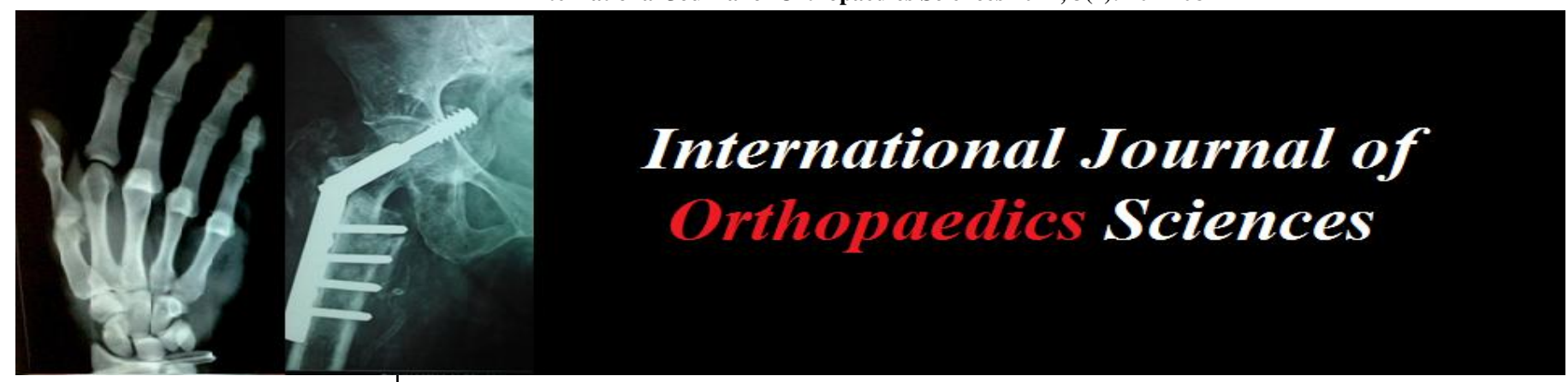

ISSN: $2395-1958$

IJOS 2017; 3(4): 704-708

(C) 2017 IJOS

www.orthopaper.com

Received: 22-08-2017

Accepted: 25-09-2017

Backiaraj Devaraj

M.S (Ortho), Assistant Professor Orthopedics Dhanalakshmi

Srinivasan Medical College and Hospital, Tamil Nadu, India

\section{Mukhesh Thangavel}

M.S (Ortho), Assistant Professor Orthopedics Dhanalakshmi Srinivasan Medical College and Hospital, Tamil Nadu, India

Dr. Vijay Anand RR D. Ortho DNB (Ortho) MRCS

Assistant Professor Orthopedics Dhanalakshmi Srinivasan

Medical College and Hospital,

Siruvachur, Perambalur,

Tamil Nadu, India

Rajkumar Nallan

M.S (ortho), Assistant Professor Orthopedics Dhanalakshmi

Srinivasan Medical College and Hospital, Tamil Nadu, India

\section{Manoranjitham}

M.S.MCH (anatomy)

Professor, Anatomy

Dhanalakshmi Srinivasan

Medical College and Hospital,

Tamil Nadu, India

Mukhesh Thangavel

M.S (ortho), Assistant Professor Dhanalakshmi Srinivasan

Medical College and Hospital

Siruvachur, Perambalur (Dt)

Tamil Nadu, India

\section{Correspondence}

Mukhesh Thangavel

M.S (Ortho), Assistant Professor Orthopedics Dhanalakshmi Srinivasan Medical College and Hospital, Tamil Nadu, India

\section{Morphometric analysis of typical cervical vertebral pedicle - An osteological study}

\author{
Backiaraj Devaraj, Mukhesh Thangavel, Dr. Vijay Anand RR, Rajkumar \\ Nallan, Manoranjitham and Mukhesh Thangavel
}

DOI: https://doi.org/10.22271/ortho.2017.v3.i4j.98

\begin{abstract}
Background: Successful placement of cervical pedicle screws requires accurate identification of entry point, trajectory and appropriate size of implant. Studies and guidelines regarding the direction of pedicle screw insertion and pedicle dimensions in Indian population are very limited and hence the objective of our study was to do Morphometric analysis of Typical Cervical Vertebral pedicle (C3 to C6)

Materials and Methods: Osteological study of the pedicle was performed in 100 typical (C3-C6) dry bone specimens. The vertebral pedicles were evaluated by measuring its height, width, length, lateral mass + pedicle length, total pedicle axis length and transverse pedicle angle.

Results: In our study, the mean pedicle length of C3, C4, C5, C6 was 6.04, 5.48, 5.30, and 5.92 respectively. The mean pedicle height in our study ranged from $5.05 \mathrm{~mm}(\mathrm{C} 3)$ to $5.86 \mathrm{~mm}(\mathrm{C} 6)$. The Range of Mean pedicle width was from 4.79 to $5.16 \mathrm{~mm}$. The mean lateral mass + pedilce length ranged from 11.17 to $13.18 \mathrm{~mm}$ while the mean total pedicle axis length ranged from 27.05 to $30.04 \mathrm{~mm}$.

Conclusions: We found that there were high individual variations. The pedicle dimensions were relatively smaller in Indians compared to previous studies in other population. This mandates preoperative CT evaluation of pedicle and smaller size pedicle screws customized according to pedicle dimensions of Indians.
\end{abstract}

Keywords: Cervical pedicle, Cervical vertebrae, Transpedicular screw fixation, Morphometry

\section{Introduction \\ Background}

Surgical procedures like transpedicular screw placement for cervical spine fixation are increasingly becoming common in recent times. Detailed knowledge of surgical anatomy and variation of the cervical vertebrae is a must for carrying out surgery effectively and safely. Although there are several clinical studies of transpedicular fixation, only few studies have been performed on cervical pedicle measurements and their projection. Successful placement of cervical pedicle screws requires accurate identification of both entry point, trajectory and appropriate size of screw. Studies and guidelines regarding the direction of pedicle screw insertion and entry point location are very limited in Indian population. Cervical pedicle screws have greater biomechanical stability ${ }^{[1]}$ besides not only allowing for shorter instrumentation with sagittal correction ${ }^{[2,3]}$. There is also the added advantage of simultaneous posterior decompression and reconstruction ${ }^{[4]}$. The accuracy varied from about only $16.8 \%$ to as high as $97 \%$ in the literature for placing screws in subaxial cervical spines ${ }^{[5,6]}$.

Proper placement of a pedicle screw in the cervical spine requires thorough understanding of the three-dimensional vertebral morphology. Because of the small size of the cervical pedicles, minor deviations from the entry point and trajectory may lead to pedicle breach, possibly resulting in neural or vascular injury ${ }^{[4]}$. Because of the catastrophic consequence of neural or vascular injuries, various surgical techniques have been developed, including the use of lamino for amenotomy to palpate the medial and superior pedicle walls, the funnel technique ${ }^{[7]}$, medial cortical pedicle screw technique ${ }^{[8]}$, cannulated screws ${ }^{[9]}$ and the computer-assisted navigation system ${ }^{[10]}$. This anatomic study was undertaken to obtain detailed Morphometric analysis of Typical Cervical Vertebrae (C3 to C6) in normal healthy adults to help in the placement of cervical screws to reduce the incidence and severity of complications caused by transpedicular screw placement. 


\section{Materials and Methods}

The present study included 104 typical cervical vertebrae (C3C6) which are a part of the osteological collection of the Department of Anatomy in our institution. Vertebra that were damaged or with deformities, which may influence measurements of pedicle were excluded from the study. Vertebrae with pedicles in good condition were studied and photographed. All linear measurements were measured using digital Vernier calliper with $0.01 \mathrm{~mm}$ precision while angular measurements were recorded with software MB ruler. The appropriate measuring site for every parameter, as well as the accuracy of measurement was determined by the authors.

Cervical pedicle morphology was evaluated by measurements of the following parameters (all paired structures were measured on each side).

1. Pedicle width (PW): Distance between the medial and lateral border of pedicle at the level of isthmus.
2. Pedicle height $(\mathrm{PH})$ : Supero-inferior diameter of the pedicle isthmus

3. Pedicle length (PL): The distance between the anterior margin of superior articular facet and posterior margin of vertebral body.

4. Lateral mass-pedicle length(LPL): distance between the posterior point on the lateral mass and the vertebral body

5. Pedicle axis length (PAL): distance between the posterior point of pedicle axis projection and the anterior-most point of the pedicle axis projection).

6. Pedicle transverse angle (PTA): The angle between pedicle axis and the sagittal plane.

7. Medial cortex of pedicle transverse angle (MCA): The angle between medial cortex of pedicle axis and the sagittal plane.

\section{Results}

Table 1: Comparison of morphometric properties of individual vertebrae between right and left sides

\begin{tabular}{|c|c|c|c|c|c|}
\hline Parameter & Parameter & $\mathrm{C3}$ & $\mathrm{C4}$ & C5 & C6 \\
\hline \multirow{3}{*}{$\begin{array}{l}\text { pedicle Height } \\
(\mathrm{mm})\end{array}$} & Right & $\begin{array}{c}5.05 \pm 0.22(4.73- \\
5.45)\end{array}$ & $5.37 \pm 0.25(5.01-5.83)$ & $5.7 \pm 0.35(5.11-6.32)$ & $5.9 \pm 0.28(5.43-6.56)$ \\
\hline & Left & $\begin{array}{c}5.06 \pm 0.23(4.77- \\
5.49)\end{array}$ & $5.4 \pm 0.21(5.11-5.8)$ & $5.76 \pm 0.34(5.32-6.54)$ & $5.82 \pm 0.41(4.91-6.53)$ \\
\hline & $\mathrm{P}$ value & 0.97 & 0.66 & 0.46 & 0.46 \\
\hline \multirow{3}{*}{$\begin{array}{l}\text { pedicle Width } \\
\qquad(\mathrm{mm})\end{array}$} & Right & $\begin{array}{c}4.78 \pm 0.23(4.43- \\
5.38)\end{array}$ & $4.84 \pm 0.23(4.43-5.43)$ & $4.95 \pm 0.35(4.54-5.81)$ & $5.17 \pm 0.35(4.71-5.97)$ \\
\hline & Left & $4.8 \pm 0.21(4.56-5.3)$ & $4.77 \pm 0.18(4.54-5.15)$ & $4.95 \pm 0.36(4.49-5.83)$ & $5.16 \pm 0.34(4.73-5.92)$ \\
\hline & $\mathrm{P}$ value & 0.73 & 0.25 & 0.89 & 0.99 \\
\hline \multirow{3}{*}{$\begin{array}{l}\text { pedicle length } \\
\qquad(\mathrm{mm})\end{array}$} & Right & $\begin{array}{c}6.04 \pm 0.32(5.54- \\
6.82)\end{array}$ & $5.47 \pm 0.4(4.81-6.13)$ & $5.31 \pm 0.35(4.75-5.98)$ & $5.92 \pm 0.35(5.11-6.43)$ \\
\hline & LEFT & $\begin{array}{l}6.03 \pm 0.34 \\
(5.52-6.88)\end{array}$ & $\begin{array}{l}5.49 \pm 0.39 \\
(4.87-6.13)\end{array}$ & $\begin{array}{l}5.29 \pm 0.31 \\
(4.80-5.93)\end{array}$ & $\begin{array}{c}5.92 \pm 0.38 \\
(5.20-6.57)\end{array}$ \\
\hline & $\mathrm{P}$ value & 0.92 & 0.86 & 0.83 & 1.00 \\
\hline \multirow{3}{*}{$\begin{array}{l}\text { Lateral Mass + Pedicle Length } \\
\qquad(\mathrm{mm})\end{array}$} & Right & $\begin{array}{c}11.18 \pm 0.84(9.86- \\
12.73)\end{array}$ & $\begin{array}{c}11.92 \pm 0.73 \\
(10.4513 .38)\end{array}$ & $\begin{array}{c}12.76 \pm 1.06(11.08- \\
14.21)\end{array}$ & $\begin{array}{c}13.25 \pm 0.7 \\
(11.7414 .65)\end{array}$ \\
\hline & Left & $\begin{array}{c}11.17 \pm 0.78(10.13- \\
12.82)\end{array}$ & $\begin{array}{c}11.8 \pm 0.65(10.39- \\
13.18)\end{array}$ & $\begin{array}{c}12.64 \pm 1.06(11.13- \\
14.31)\end{array}$ & $\begin{array}{c}13.1 \pm 0.76(11.73- \\
14.45)\end{array}$ \\
\hline & $\mathrm{P}$ value & 0.95 & 0.54 & 0.79 & 0.46 \\
\hline \multirow{3}{*}{$\begin{array}{l}\text { Total axial length } \\
(\mathrm{mm})\end{array}$} & Right & $\begin{array}{c}27.03 \pm 1.96(23.58- \\
29.74)\end{array}$ & $\begin{array}{c}28.27 \pm 1.67(24.43- \\
30.81)\end{array}$ & $\begin{array}{c}29.61 \pm 1.34(27.47- \\
33.28)\end{array}$ & $\begin{array}{c}30.18 \pm 1.39 \\
(27.93-33.81) \\
\end{array}$ \\
\hline & Left & $\begin{array}{c}27.07 \pm 2.03(23.3- \\
30.09)\end{array}$ & $\begin{array}{c}28.29 \pm 1.72(24.6- \\
30.81)\end{array}$ & $\begin{array}{c}29.66 \pm 1.33(27.48- \\
33.42)\end{array}$ & $\begin{array}{c}29.89 \pm 1.33(27.57- \\
33.61)\end{array}$ \\
\hline & $\mathrm{P}$ value & 0.94 & 0.96 & 0.91 & 0.45 \\
\hline \multirow{3}{*}{$\begin{array}{l}\text { Transverse Pedicle angle } \\
\text { (mm) }\end{array}$} & Right & $\begin{array}{c}44.6 \pm 3.56 \\
(33-48)\end{array}$ & $\begin{array}{c}43.08 \pm 3.49 \\
(33-50)\end{array}$ & $\begin{array}{c}43.63 \pm 3.44 \\
(36-50)\end{array}$ & $42.12 \pm 2.98(38-46)$ \\
\hline & Left & $43.68 \pm 3.02(35-48)$ & $42.96 \pm 3.49(34-50)$ & $44.16 \pm 4.17(37-53)$ & $41.96 \pm 3.13(37-47)$ \\
\hline & $\mathrm{P}$ value & 0.33 & 0.90 & 0.80 & 085 \\
\hline
\end{tabular}

\section{Pedicle Height}

The mean pedicle Height of vertebrae c3 in right was 5.05 and in left was 5.06 as shown in table 1 .The mean pedicle Height of vertebrae c4 in right was 5.37 and the c4 in left was 5.4.The mean pedicle Height of vertebrae c5 in right was 5.7 and the c5in left was 5.76. The mean pedicle Height of vertebrae c6 in right was 5.9 and the c6 in left was 5.82. The association between right and left was statistically not significant at all the four levels ( $\mathrm{P}$ value $>0.05$ ). The mean bilateral pedicle height of vertebrae C3, C 4, C 5 and C6 was $5.05,5.38,5.72$, and 5.86 respectively.

\section{Pedicle width}

The mean pedicle Width of vertebrae $\mathrm{c} 3$ in right was 4.78 and the $\mathrm{c} 3$ in left was 4.8 as shown in table 1 . The mean pedicle Width of vertebrae c4 in right was 4.84 and the $\mathrm{c} 4$ in left was 4.77. The mean pedicle Width of vertebrae c5 in right was 4.95 and the c5in left was 4.95 . The mean pedicle Width of vertebrae c6 in right was 5.17 and the c6 in left was 5.16. The association between right and left was statistically not significant at all the four levels ( $\mathrm{P}$ value $>0.05$ ). The mean bilateral pedicle width of vertebrae C3, C 4, C 5 and C6 was $4.79,4.8,4.94$, and 5.16 respectively.

\section{Pedicle Length}

The mean pedicle length of vertebrae C3 in right was 6.04 and the $\mathrm{C} 3$ in left was 6.03 as shown in table 1 . The mean pedicle length of vertebrae $\mathrm{c} 4$ in right was 5.47 and the $\mathrm{C} 4$ in left was 5.49. The mean pedicle length of vertebrae C5 in right was 5.31 and the c5in left was 5.29. The mean pedicle length of vertebrae C6 in right was 5.92 and the c6 in left was 5.92. The association between right and left was statistically not significant at all the four levels ( $\mathrm{P}$ value $>0.05$ ). The mean bilateral pedicle length of vertebrae C3, C 4, C 5 and C6 was $6.04,5.48,5.30$, and 5.92 respectively.

\section{Lateral Mass + Pedicle Length}

The mean lateral mass + pedicle length of vertebrae $\mathrm{c} 3$ in 
right was 11.18 and the $\mathrm{c} 3$ in left was 11.17. The mean pedicle Lateral Mass - Pedicle Length of vertebrae c4 in right was 11.92 and the $\mathrm{c} 4$ in left was 11.8.The mean pedicle Lateral Mass - Pedicle Length of vertebrae c5 in right was 12.76 and the c5in left was 12.64.The mean pedicle Lateral Mass - Pedicle Length of vertebrae c6 in right was 13.25 and the c6 in left was 13.1. The association between right and left was statistically not significant at all the four levels ( $P$ value $>0.05)$. The mean bilateral lateral mass + pedicle length of vertebrae C3, C 4, C 5 and C6 was 11.17, 11.86, 12.68, and 13.18 respectively.

\section{Total pedicle axis length:}

The mean total axial length of vertebrae c3 in right was 27.03 and the $\mathrm{C} 3$ in left was 27.07. The mean total axial length of vertebrae c4 in right was 28.27 and the $\mathrm{C} 4$ in left was 28.29 , The mean total axial length of vertebrae c5 in right was 29.61 and the C5in left was 29.66, The mean total axial length of vertebrae c6 in right was 30.18 and the C6 in left was 29.89 . The association between right and left was statistically not significant at all the four levels ( $P$ value $>0.05)$. The mean bilateral total axial length of vertebrae C3, C 4, C 5 and C6 was $27.05,28.28,29.63$, and 30.04 respectively.

\section{Transverse Pedicle angle}

The mean Transverse Pedicle angle of vertebrae c3 in right was 44.6 and the c3 in left was 43.68. The mean Transverse Pedicle angle of vertebrae $\mathrm{c} 4$ in right was 43.08 and the $\mathrm{c} 4$ in left was 42.96.The mean Transverse Pedicle angle of vertebrae c5 in right was 43.63 and the c5in left was 44.16. The mean Transverse Pedicle angle of vertebrae c6 in right was 42.12 and the $c 6$ in left was 41.96. The association between right and left was statistically not significant at all the four levels ( $\mathrm{P}$ value>0.05). The mean Transverse Pedicle Angle of vertebrae C3, C 4, C 5 and C6 was 44.14, 43.02, 44.02 , and 42.04 respectively.

Table 2: Summary of average Morphological parameters of typical cervical vertebrae

\begin{tabular}{|c|c|c|c|c|}
\hline Bilateral & C3 & $\mathrm{C} 4$ & C5 & C6 \\
\hline Pedicle Height $(\mathrm{mm})$ & $5.05 \pm 0.22(4.79-5.47)$ & $5.38 \pm 0.23(5.06-5.815)$ & $5.72 \pm 0.33(5.225-6.43)$ & $5.86 \pm 0.33(5.17-6.545)$ \\
\hline $\begin{array}{c}\text { pedicle Width } \\
(\mathrm{mm})\end{array}$ & $4.79 \pm 0.22(4.525-5.34)$ & $\begin{array}{c}4.8 \pm 0.18 \\
(4.54-5.15) \\
\end{array}$ & $4.94 \pm 0.33(4.54-5.82)$ & $5.16 \pm 0.34(4.74-5.945)$ \\
\hline $\begin{array}{l}\text { pedicle length } \\
(\mathrm{mm})\end{array}$ & $\begin{array}{r}6.04 \pm 0.33 \\
(5.82-6.29 \\
\end{array}$ & $\begin{array}{c}5.48 \pm 0.39 \\
(5.18-5.80) \\
\end{array}$ & $\begin{array}{c}5.30 \pm 0.32 \\
(5.04-5.51) \\
\end{array}$ & $\begin{array}{c}5.92 \pm 0.36 \\
(5.66-6.23) \\
\end{array}$ \\
\hline Lateral Mass Length (mm) & $\begin{array}{c}11.17 \pm 0.8(10.045- \\
12.77)\end{array}$ & $\begin{array}{c}11.86 \pm 0.67(10.42- \\
13.23)\end{array}$ & $\begin{array}{c}12.68 \pm 1.05(11.13- \\
14.26)\end{array}$ & $\begin{array}{c}13.18 \pm 0.71(11.735- \\
14.55)\end{array}$ \\
\hline $\begin{array}{l}\text { Total Axial Length } \\
(\mathrm{mm})\end{array}$ & $\begin{array}{c}27.05 \pm 1.99(23.44- \\
29.915) \\
\end{array}$ & $\begin{array}{c}28.28 \pm 1.69(24.515- \\
30.81)\end{array}$ & $\begin{array}{c}29.63 \pm 1.34(27.475- \\
33.35) \\
\end{array}$ & $\begin{array}{c}30.04 \pm 1.34(27.75- \\
33.71)\end{array}$ \\
\hline $\begin{array}{l}\text { Transverse pedicle Angle } \\
(\mathrm{mm})\end{array}$ & $\begin{array}{c}44.14 \pm 3.2 \\
(34-48)\end{array}$ & $\begin{array}{c}43.02 \pm 3.4 \\
(34-50)\end{array}$ & $44.02 \pm 3.81(36.5-51.5)$ & $\begin{array}{c}42.04 \pm 3 \\
(37.5-46.5) \\
\end{array}$ \\
\hline
\end{tabular}
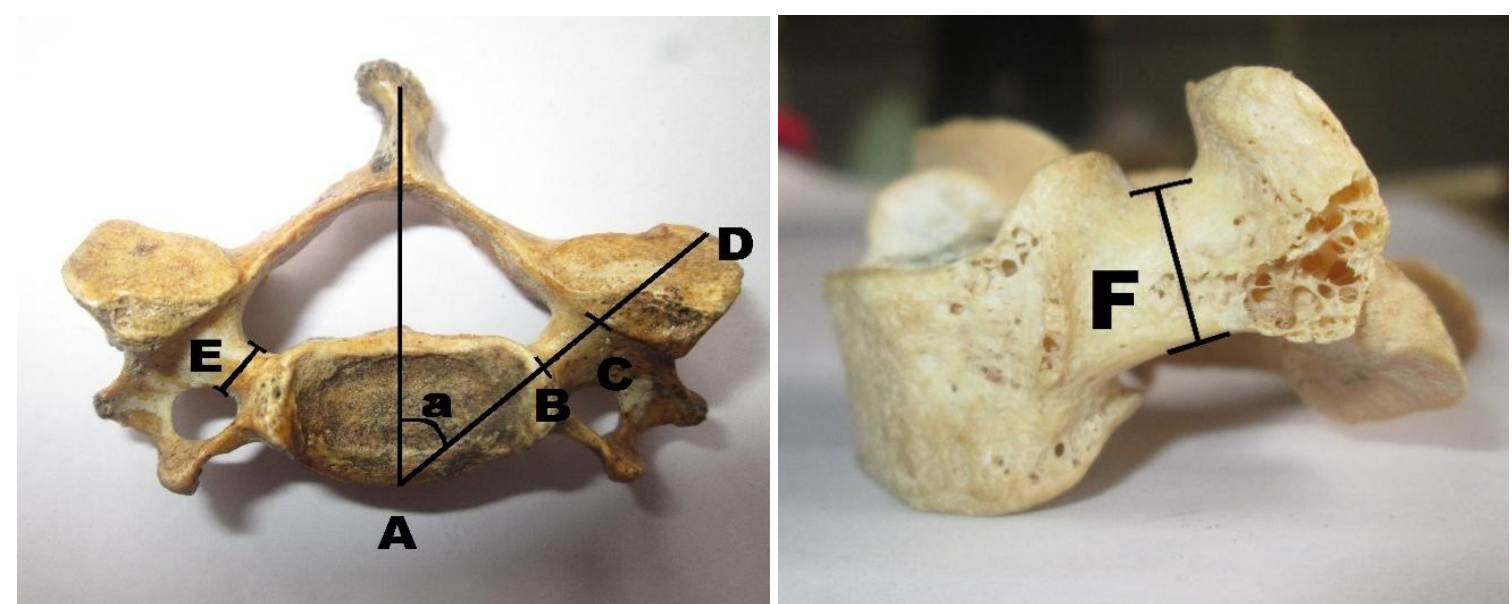

A-The most anterior aspect of vertebral body along the extension of the pedicle axis line

$\mathrm{B}-$ The most posterior aspect of vertebral body along the extension of the pedicle axis line

C-The most posterior aspect of pedicle along the pedicle axis line

$\mathrm{D}$-The most posterior aspect of the facet along the pedicle axis line

$\mathrm{D}-\mathrm{A}$ distance $=$ total axial length along the pedicle axis

$\mathrm{D}-\mathrm{B}$ distance $=$ lateral mass and pedicle length along the pedicle axis

$\mathrm{C}-\mathrm{B}$ DISTANCE$=$ length of pedicle along the pedicle axis

$\mathrm{E}=$ Width of the pedicle at the level of isthmus

$\mathrm{F}=$ Height of pedicle at the level of isthmus

$\mathrm{a}=$ sagittal pedicle angle

\section{Discussion}

The human spinal cord consists of nerves that connect the brain to nerves in the body. Vertebrae are the 33 individual bones that interlock with each other to form the spinal column. They alternate with intervertebral discs to form the spinal column and protect the spinal cord. These vertebrae vary in their size, shape although their basic structure is similar. There are 7 cervical, 12 thoracic and 5 lumbar vertebrae, which are termed free while the 5 sacral and 4 coccygeal vertebrae are fixed. The cervical vertebrae are identified by the presence of foramina transversaria in their transverse processes. Although being the smallest, the cervical vertebrae exhibit the greatest range of movements making them prone to a variety of traumatic and degenerative conditions. Sometimes it requires surgical fusion of adjacent vertebrae with implants. Posterior stabilization and fusion can 
be accomplished by ether lateral mass screw or pedicle screw fixation. The correct placement of screws is very important for preventing damage to the vertebral artery, spinal medulla or nerve roots [7, 11]. One of the superior approaches of arthrodesis is Trans-pedicular screw. There is a need for detailed anatomical knowledge in the Indian population as the instrumentation involves damage to various vital structures, and also there is a variability in vertebral dimensions amongst different races [12-19] thus causing difficulty in the standardization of measurements.

The characteristic of a typical cervical vertebrae is the presence of transversely elongated bodies. The pedicles are short cylindrical processes which project backwards from the body that meet the laminae posteriorly. The intervertebral foramina through which the spinal nerves pass through is formed by the vertebral notching which is present on the superior and inferior aspects of the pedicle. Hence, the length and width of the pedicle are important for selecting the screw size during transpedicular fixation since lack of knowledge of these parameters may lead to increased risk of damage to neuro vascular structures.
In our study, the mean pedicle length of $\mathrm{C} 3, \mathrm{C} 4, \mathrm{C} 5, \mathrm{C} 6$ was $6.04,5.48,5.30$, and 5.92 respectively as shown in table 2 . It was similar to that reported by Bozbuga, M., et al (2004) ${ }^{[12]}$ with a mean length of $5.75 \mathrm{~mm}$ in 28 cervical columns in Turkey, while Saluja $S$ et al (2015) ${ }^{[20]}$ reported a mean length of $4.51 \pm 0.66 \mathrm{~mm}$ on 203 typical cervical vertebrae in indian population, which was lower than our study. The mean pedicle height in our study ranged from $5.05 \mathrm{~mm}(\mathrm{C} 3)$ to 5.86 mm (C6) as shown in table 1. Gupta, R., et al. (2013) ${ }^{[14]}$ reported a mean pedicle height of $6.5 \pm 1.1 \mathrm{~mm}$ which was much greater than our study. In our study, the mean pedicle height of C3 was $5.05 \pm 0.22$ while Kayalioglu, G., et al. (2007) ${ }^{[21]}$ reported a mean C3 pedicle height of $5.93 \pm 0.87$ much higher than our study and also for C4. The Mean pedicle width of 4.79 to $5.16 \mathrm{~mm}$ in our study was similar to that reported by other authors $[12,14]$. The mean transverse pedicle angle in our study ranged from 42.04 to 44.14 degrees as shown in table 2, similar to that reported by Saluja $\mathrm{S}$ et al (2015) ${ }^{[20]}$. Gupta, R., et al. (2013) ${ }^{[14]}$ reported a lower angle of 39.4 in their study.

Table 3: Comparison of Characteristics of Cervical Pedicle

\begin{tabular}{|c|c|c|c|c|}
\hline Author & $\begin{array}{l}\text { Mean Pedicle } \\
\text { Length (Mm) }\end{array}$ & $\begin{array}{c}\text { Mean Pedicle Width } \\
\text { (Mm) }\end{array}$ & $\begin{array}{c}\text { Mean Pedicle Height } \\
(\mathrm{Mm})\end{array}$ & $\begin{array}{c}\text { Mean Pedicle Transverse } \\
\text { Angle (Degree) }\end{array}$ \\
\hline \multirow{5}{*}{ Our Present Study } & $\begin{array}{c}5.30 \text { to } 6.04 \\
\text { (Range of mean) }\end{array}$ & $\begin{array}{c}4.79 \text { to } 5.16 \text { (Range of } \\
\text { mean) }\end{array}$ & $\begin{array}{c}5.05 \text { to } 5.86 \text { (Range of } \\
\text { mean) }\end{array}$ & $\begin{array}{c}42.04 \text { to } 44.14 \text { (Range of } \\
\text { mean) }\end{array}$ \\
\hline & $6.04 \pm 0.33(\mathrm{C} 3)$ & $4.79 \pm 0.22(\mathrm{C} 3)$ & $5.05 \pm 0.22(\mathrm{C} 3)$ & $44.14 \pm 3.2(\mathrm{C} 3)$ \\
\hline & $5.48 \pm 0.39(\mathrm{C} 4)$ & $4.8 \pm 0.18(\mathrm{C} 4)$ & $5.38 \pm 0.23(\mathrm{C} 4)$ & $43.02 \pm 3.4(\mathrm{C} 4)$ \\
\hline & $5.30 \pm 0.32(\mathrm{C} 5)$ & $4.94 \pm 0.33(\mathrm{C} 5)$ & $5.72 \pm 0.33(\mathrm{C} 5)$ & $44.02 \pm 3.81(\mathrm{C} 5)$ \\
\hline & $5.92 \pm 0.36(\mathrm{C} 6)$ & $5.16 \pm 0.34(\mathrm{C} 6)$ & $5.86 \pm 0.33(\mathrm{C} 6)$ & $42.04 \pm 3(\mathrm{C} 6)$ \\
\hline SalujaS et al $(2015)^{[20]}$ & $4.51+/-0.66$ & $4.56 \pm 0.43$ & - & $44.47 \pm 2.81$ \\
\hline $\begin{array}{c}\text { Gupta, R., et al. }{ }^{[14]} \\
(2013)\end{array}$ & $401-19000$ & $4.9 \pm 0.9$ & $6.5 \pm 1.1$ & 39.4 \\
\hline $\begin{array}{l}\text { Kayalioglu, G., et al. } \\
\text { (2007) }\end{array}$ & $\begin{array}{l}6.15 \pm 1.38(\mathrm{C} 3) \\
6.14 \pm 1.19(\mathrm{C} 4)\end{array}$ & $\begin{array}{l}4.16 \pm 0.76(\mathrm{C} 3) \\
4.57 \pm 0.74(\mathrm{C} 4)\end{array}$ & $\begin{array}{l}5.93 \pm 0.87(\mathrm{C} 3) \\
6.24 \pm 0.79(\mathrm{C} 4)\end{array}$ & $\begin{array}{l}- \\
-\end{array}$ \\
\hline $\begin{array}{l}\text { Bozbuga, M., et al } \\
(2004)^{[12]} \text {. }\end{array}$ & 5.75 & 4.65 & 6.7 to 7.2 & 46.9 \\
\hline
\end{tabular}

In our study, there was statistically no significant difference between the pedicle height, width, length, transverse pedicle angle, total axial length, Lateral Mass - Pedicle Length on the right and left sides in all the examined cervical vertebrae $(\mathrm{C} 3$, C4, C5, C6).

The mean lateral mass+ pedicle length of vertebrae ranged from 11.17 to $13.18 \mathrm{~mm}$ which was lesser than that reported by Bozbuga, M., et al (2004) ${ }^{[12]}$ with 15.3 to $16.0 \mathrm{~mm}$. We reported the mean total pedicle axis length ranging from 27.05 to $30.04 \mathrm{~mm}$ which was lesser than that reported by Bozbuga, M., et al (2004) ${ }^{[12]}$ who reported a pedicle axis length of 22.2 to $27.7 \mathrm{~mm}$.

Anatomic variations in the size of the cervical pedicles limit the application of pedicle screws. Large or long pedicle screws and unrecognized screw misplacement may result in pedicle fracture or damage of important neurovascular structures. It is necessary that a clear cut anatomical knowledge is required before attempting the cervical pedicle screw application.

\section{Conclusion}

The present results show high individual variations in many parameters which is concordant with other studies, highlighting the risk of damaging important neurovascular structures during transpedicular screw fixation. We recommend routine use of CT scanogam of pedicle for preoperative planning. But comparing to previous studies, our
Indian population, has overall smaller values of the pedicle dimensions and the pedicle screw must be customized accordingly.

There is a considerable technical challenge during transpedicular stabilization of the cervical spine to the surgeons, who require an extensive knowledge of the surgical anatomy of cervical vertebrae.

Our present study yielded the characteristics of the Indian cervical vertebrae. We found the dimensions of the vertebrae is variable and lesser in Indians when compared to other population. This knowledge about typical cervical vertebrae, its pedicle and their adjacent neurovascular structures may enhance the safety of transpedicular screw insertion.

\section{References}

1. Zheng X, Chaudhari R, Wu C, Mehbod AA, Transfeldt EE. Subaxial cervical pedicle screw insertion with newly defined entry point and trajectory: accuracy evaluation in cadavers. European Spine Journal. 2010; 19(1):105-12.

2. Johnston TL, Karaikovic EE, Lautenschlager EP, Marcu D. Cervical pedicle screws vs. lateral mass screws: uniplanar fatigue analysis and residual pullout strengths. Spine J. 2006; 6(6):667-72.

3. Jones EL, Heller JG, Silcox DH, Hutton WC. Cervical pedicle screws versus lateral mass screws. Anatomic feasibility and biomechanical comparison. Spine (Phila Pa 1976). 1997; 22(9):977-82. 
4. Abumi K, Kaneda K, Shono Y, Fujiya M. One-stage posterior decompression and reconstruction of the cervical spine by using pedicle screw fixation systems. J Neurosurg. 1999; 90(1 Suppl):19-26.

5. Reinhold M, Magerl F, Rieger M, Blauth M. Cervical pedicle screw placement: feasibility and accuracy of two new insertion techniques based on morphometric data. Eur Spine J. 2007; 16(1):47-56.

6. Miller RM, Ebraheim NA, Xu R, Yeasting RA. Anatomic consideration of transpedicular screw placement in the cervical spine. An analysis of two approaches. Spine (Phila Pa 1976). 1996; 21(20):2317-22.

7. Karaikovic EE, Yingsakmongkol W, Gaines RW, Jr. Accuracy of cervical pedicle screw placement using the funnel technique. Spine (Phila $\mathrm{Pa}$ 1976). 2001; 26(22):2456-62.

8. Mahesh B, Upendra B, Mahan RS. The medial cortical pedicle screw--a new technique for cervical pedicle screw placement with partial drilling of medial cortex. Spine J 2014; 14(2):371-80.

9. Richter M, Cakir B, Schmidt R. Cervical pedicle screws: conventional versus computer-assisted placement of cannulated screws. Spine (Phila Pa 1976). 2005; 30(20):2280-7.

10. Richter M, Mattes T, Cakir B. Computer-assisted posterior instrumentation of the cervical and cervicothoracic spine. Eur Spine J. 2004; 13(1):50-9.

11. Karaikovic EE, Daubs MD, Madsen RW, Gaines RW Jr. Morphologic characteristics of human cervical pedicles. Spine (Phila Pa 1976). 1997; 22(5):493-500.

12. Bozbuga M, Ozturk A, Ari Z, Sahinoglu K, Bayraktar B, Cecen A. Morphometric evaluation of subaxial cervical vertebrae for surgical application of transpedicular screw fixation. Spine (Phila Pa 1976). 2004; 29(17):1876-80.

13. Ebraheim NA, $\mathrm{Xu} \mathrm{R}$, Knight $\mathrm{T}$, Yeasting RA. Morphometric evaluation of lower cervical pedicle and its projection. Spine (Phila Pa 1976). 1997; 22(1):1-6.

14. Gupta R, Kapoor K, Sharma A, Kochhar S, Garg R. Morphometry of typical cervical vertebrae on dry bones and CT scan and its implications in transpedicular screw placement surgery. Surg Radiol Anat. 2013; 35(3):181-9.

15. Herrero CF, Luis do Nascimento A, Maranho DA, Ferreira-Filho NM, Nogueira CP, Nogueira-Barbosa MH et al. Cervical pedicle morphometry in a Latin American population: A Brazilian study. Medicine (Baltimore). 2016; 95(25):e3947.

16. Chatzigianni A, Halazonetis DJ. Geometric morphometric evaluation of cervical vertebrae shape and its relationship to skeletal maturation. Am J Orthod Dentofacial Orthop. 2009; 136(4):481.e1-9; discussion 3.

17. Chen C, Ruan D, Wu C, Wu W, Sun P, Zhang Y et al. CT morphometric analysis to determine the anatomical basis for the use of transpedicular screws during reconstruction and fixations of anterior cervical vertebrae. PLoS One. 2013; 8(12):e81159.

18. Feng H, Fang XY, Huang DG, Yu CC, Li HK, Zhao SC et al. A morphometric study of the middle and lower cervical vertebral endplates and their components. Medicine (Baltimore). 2017; 96(10):e6296.

19. Feng $H$, Fang $X$, Huang D, Yu C, Zhao S, Hao D. Quantitative morphometric study of the subaxial cervical vertebrae end plate. Spine J. 2017; 17(2):269-76.

20. Saluja S, Patil S, Vasudeva N. Morphometric Analysis of Sub-axial Cervical Vertebrae and Its Surgical
Implications. J Clin Diagn Res. 2015; 9(11):Ac01-4.

21. Kayalioglu G, Erturk M, Varol T, Cezayirli E. Morphometry of the cervical vertebral pedicles as a guide for transpedicular screw fixation. Neurol Med Chir (Tokyo). 2007; 47(3):102-7; discussion 7-8. 